\title{
Childhood Anaplastic Ependymoma
}

National Cancer Institute

\section{Source}

National Cancer Institute. Childhood Anaplastic Ependymoma. NCI Thesaurus. Code C124293.

An anaplastic ependymoma that occurs during childhood. 